\title{
Large-vessel occlusion, large thrombus burden acute stroke in acute pulmonary embolism: A single multi-specialty multi-skill team treatment optimization
}

\author{
Łukasz Tekieli1-4, Tomasz Tomaszewski ${ }^{2,4,5}$, Robert Musiał ${ }^{4,6}$, Magdalena Lipińska-Strasik ${ }^{4,6}$, \\ Małgorzata Urbańczyk-Zawadzka ${ }^{4,7}$, R Paweł Banyś ${ }^{7}$, Renata Maksoń2, Łukasz Wiewiórka ${ }^{2,3,7}$, \\ Joanna Adamczyk-Dylewska ${ }^{8}$, Iris Q Grunwald ${ }^{9}$, Piotr Musiałek ${ }^{1,2,4}$
}

\author{
'Department of Cardiac and Vascular Diseases, Institute of Cardiology, Jagiellonian University Medical College, Kraków, Poland \\ ${ }^{2}$ John Paul II Hospital, Kraków, Poland \\ ${ }^{3}$ Department of Interventional Cardiology, Institute of Cardiology, Jagiellonian University Medical College, Kraków, Poland \\ ${ }^{4}$ Thrombectomy-Capable Stroke Center, John Paul II Hospital, Kraków, Poland \\ ${ }^{5}$ Department of Neurology, John Paul II Hospital, Kraków, Poland \\ ${ }^{6}$ Department of Anesthesiology and Intensive Therapy, John Paul II Hospital, Kraków, Poland \\ 7Department of Radiology, John Paul II Hospital, Kraków, Poland \\ ${ }^{8}$ Quality Assurance Division, John Paul II Hospital, Kraków, Poland \\ ${ }^{9}$ Chair of Neuroradiology, Department of Radiology, University of Dundee, Ninewells Hospital, Dundee, Scotland, United Kingdom
}

\author{
Correspondence to: \\ Łukasz Tekieli, MD, PhD, \\ Department of Cardiac and \\ Vascular Diseases, \\ Institute of Cardiology, \\ Jagiellonian University \\ Medical College, \\ Prądnicka 80, 31-202 Kraków \\ Poland, \\ phone: +48 1261422 87, \\ e-mail: luk.tekieli@gmail.com \\ Copyright by the Author(s), 2021 \\ Kardiol Pol. 2021; \\ 79 (12): 1382-1384; \\ DOI: 10.33963/KP.a2021.0126 \\ Received: \\ October 6, 2021 \\ Revision accepted: \\ October 7, 2021 \\ Published online: \\ October 7, 2021
}

A fully independent 74-year-old man with no significant morbidities was found at 10:55 AM with aphasia and right-sided hemiparesis. He was last seen well at 07:30 AM. Thrombectomy-Capable Stroke Center emergency admission occurred at 11:37 AM. The National Institute of Health Stroke Scale score was 24. There was also a marked respiratory effort with arterial blood oxygen desaturation to $88 \%$. Arterial blood pressure was 100/70 mm Hg; heart rate $115-120 / \mathrm{min}$. Plain computed tomography $(C T ; 11: 49 A M)$ showed early signs of left-hemispheric anterior circulation infarction without intracerebral bleed (Figure 1A, Alberta Stroke Program Early Computed Tomography Score 7). A hyperdense middle cerebral artery (MCA) sign was present (Figure 1A, inset). Intravenous thrombolysis (stroke protocol) was initiated. CT angiography (11:57 AM) revealed (1) the left internal carotid artery (LICA) intracranial segment occlusion extending to the MCA M1 segment; and (2) massive, bilateral pulmonary embolism (PE; Figure 1B) with the right ventricular enlargement (RV/LV ratio $>1$; Figure 1C). The PE Severity Index was high at 134 (30-day PE death risk, 10\%-24.5\%). A cerebral mechanical thrombectomy (MT) window was maintained [1]. Norepinephrine infusion was started to increase systolic arterial blood pressure to $\approx 140-160 \mathrm{~mm} \mathrm{Hg}$ to enhance cerebral collateral blood supply as the cerebral autoregulation spontaneous hypertensive response was likely offset by the PE effect. The interventional management team (stroke neurologist, anesthetist, and 2 stroke MT-certified cardio-angiologists) had been activated, consistent with the institutional standard operating procedure. The management plan included immediate cerebral mechanical reperfusion [2,3] followed by a catheter-based pulmonary thrombus load reduction [4]. At 12:16 PM the patient entered our cerebral intervention-compatible angio suite (intubation 12:20 PM). Optimal-result cerebral thrombectomy was performed (Figure 1E, F; first-pass complete aspiration; angiographic full reperfusion in absence of distal embolism; 12:47 PM).

The troponin I level lab evaluation, available at the cerebral embolectomy completion point, was $0.146 \mathrm{ng} / \mathrm{ml}$ (normal level $\leq 0.014 \mathrm{ng} / \mathrm{ml}$ ), consistent with the RV myocardial strain-related injury with the PE load (renal function normal). A continued intervention plan involved proceeding to the pulmonary thrombus load reduction using a clot separa- 

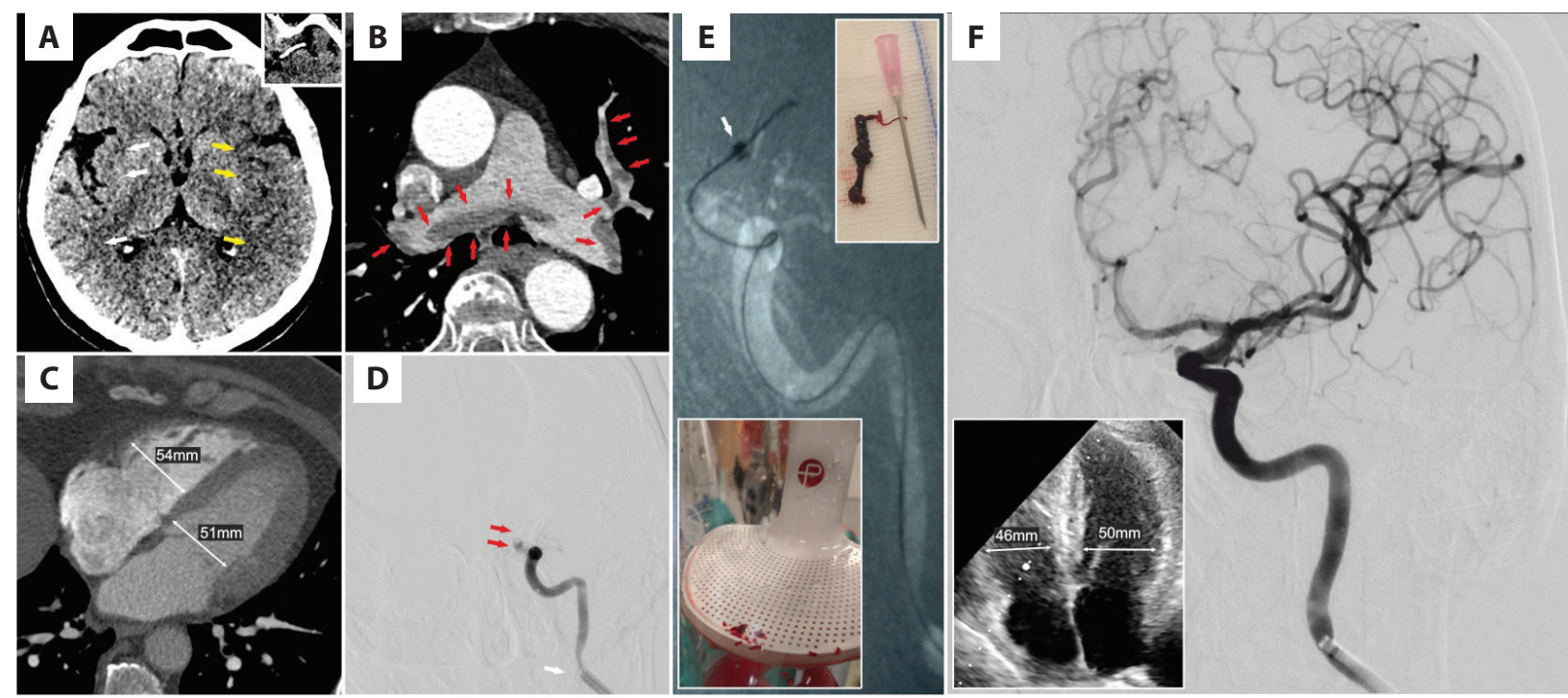

Figure 1. Diagnostic and procedural imaging in a patient presenting with acute, major left hemispheric stroke and increased respiratory effort with markedly reduced arterial blood saturation. Early signs of left-hemispheric infarction (ASPECTS 7) with hyperdense middle cerebral artery (inset) on emergent plain CT (A) prompted immediate intravenous thrombolysis. CT angiography showed massive PE (B, red arrows) with enlarged right ventricle (C), and LICA intracranial T-occlusion (red double-arrow on subsequent catheter angiography in D). Vacuum pump-assisted (E, bottom-left inset) cerebral mechanical aspiration involved a dedicated large-bore aspiration catheter (Jet 7, Penumbra, E). A large embolus was retrieved en-block (E, top-right inset) with several additional small emboli visible in the aspiration pump filter (E, bottom-left). There was an immediate "first-pass" optimal cerebral reperfusion effect (F). Stand-by transition to PE catheter embolectomy (pulmonary clot separator-assisted vacuum aspiration, Indigo Mechanical Thrombectomy System; pump in E) was deterred due to RV dilation reduction on echocardiography (F, bottom-left inset) and hemodynamic improvement likely resulting from the PE magnitude reduction with ongoing IV thrombolysis. For detailed legend and transesophageal echocardiography see Supplementary material

Abbreviations: CT, computed tomography; LICA, left internal carotid artery; PE, pulmonary embolism; RV, right ventricle

tor-assisted aspiration technique (Indigo 8F system [4]; aspiration pump in Figure 1E). However, RV function improvement (RV/LV ratio < 1.0; Figure 1E inset) and hemodynamic stabilization were noted (spontaneous blood pressure $110 / 75 \mathrm{~mm} \mathrm{Hg}$, heart rate $95 / \mathrm{min}$ ), likely following systemic thrombolysis. The PE transcatheter intervention was thus deferred, and the patient was transferred to the Intensive Care Unit. After cerebral control, CT excluded intracranial bleed, intravenous (IV) unfractionated heparin infusion was started for continued PE pharmacological treatment (at an activated partial thromboplastin time maintained at the lower limit of thetherapeutic range). Twelve days later, the patient was transferred to a neuro-rehabilitation center. $\mathrm{He}$ is scheduled for patent foramen ovale (a mechanistic link between PE and acute embolic stroke; Supplementary material, Figure S1) percutaneous closure.

Our fundamental considerations have included:

- Paramount role of minimizing the time from stroke onset to reperfusion (see Supplementary material, Figure S1 for MR PREDICTS [www.mrclean-trial.org/mr-predicts. html] absolute and relative patient benefit calculations in carotid T-occlusion).

- Counteracting cerebral injury aggravation with PE-generated arterial blood desaturation, arterial hypotension and hemodynamic instability.

- Any potential transportation attempt to the nearest Comprehensive Stroke Center (Level-1 stroke center) would have placed this patient, like many others [1,
$2,5]$, beyond the MT therapeutic window (on top of challenges of a hemodynamically unstable patient Comprehensive Stroke Center acceptance and inter-hospital transfer logistics), depriving the patient of guideline-mandated care [1].

Patients and healthcare systems may benefit from developing and maintaining cardio-angiology vascular operator multi-area skills that should, in geographies with unmet need in particular, include acute stroke interventions within a trained team with local stroke neurology $[2,5]$. With unquestionable evidence of the large negative impact of transportation-inflicted delays on MT clinical efficacy, the patients who can be treated on-site should be treated on-site - rather than losing their MT benefit (cerebral tissue) en route to external level-1 stroke centres [2].

\section{Supplementary material}

Supplementary material is available at https://journals. viamedica.pl/kardiologia_polska.

\section{Article information}

Acknowledgments: The authors would like to acknowledge operator and team training from the World Federation for Interventional Stroke Treatment (WIST). Special thanks to Helen Donald-Simpson MSc, University of Dundee, Tayside Innovation Medtech Ecosystem (TIME-Stroke), and to the clinical team of Ninewells Hospital Department of Radiology, Dundee, Scotland, United Kingdom. Special thanks to Ms Ewa Weglarz, RN MSc., John Paul II Hospital Thombectomy-capable Stroke Centre Cathlab Manager. 
Conflict of interest: Piotr Musiałek is the Polish Cardiac Society Board Representative for Stroke and Vascular Interventions.

Open access: This article is available in open access under Creative Common Attribution-Non-Commercial-No Derivatives 4.0 International (CC BY-NC-ND 4.0) license, allowing to download articles and share them with others as long as they credit the authors and the publisher, but without permission to change them in any way or use them commercially. For commercial use, please contact the journal office at kardiologiapolska@ptkardio.pl.

How to cite: Tekieli Ł, Tomaszewski T, Musiał R, et al. Large-vessel occlusion, large thrombus burden acute stroke in acute pulmonary embolism: A single multi-specialty multi-skill team treatment optimization. Kardiol Pol. 2021; 79(12): 1382-1384, doi: 10.33963/KP.a2021.0126.

\section{REFERENCES}

1. Musiałek P, Kowalczyk ST, Klecha A. Where and how to treat a man presenting up to 4 hours after cerebral large-vessel occlusion to a thrombec- tomy-capable major regional hospital. Kardiol Pol. 2020; 78(4):354-356, doi: 10.33963/KP.15303, indexed in Pubmed: 32336070.

2. Grunwald IQ, Podlasek A, Nizankowski R. Cardiology CathLab-based multispecialty stroke thrombectomy - Poland is moving on! Kardiol Pol. 2021; 79(6): 612-613, doi: 10.33963/KP.a2021.0032, indexed in Pubmed: 34196373.

3. Tekieli L, Banaszkiewicz K, Moczulski Z, et al. Novel Large-Diameter Controlled-Expansion Stentriever, Embolic-Prevention Stent and Flow Reversal in Large-Thrombus-Burden ICA Proximal Occlusion Stroke. JACC Cardiovasc Interv. 2021; 14(21): e287-e291. doi: 10.1016/j.jcin.2021.07.050, indexed in Pubmed: 34656497

4. Araszkiewicz A, Sławek-Szmyt S, Jankiewicz S, et al. Continuous aspiration thrombectomy in high-and intermediate-high-risk pulmonary embolism in real-world clinical practice. J Interv Cardiol. 2020; 2020: 4191079, doi: 10.1155/2020/4191079, indexed in Pubmed: 32904502.

5. Musiałek P, Montauk L, Saugnet A, et al. The cardio-vascular future of panvascular medicine: the basics. Kardiol Pol. 2019; 77(10): 899-901, doi: 10.33963/KP.15034, indexed in Pubmed: 31651911. 